\title{
Mining Social Media Data of Philippine Higher Education Institutions Using Naïve Bayes Classifier Algorithm
}

\author{
Prof. Joey S. Aviles ${ }^{1+}$ and Dr. Rosanna A. Esquivel ${ }^{2+}$ \\ ${ }^{1}$ Panpacific University North Philippines - Tayug Campus Inc. \\ ${ }^{2}$ Angeles University Foundation
}

\begin{abstract}
Higher Education Institutions in the Philippines integrate social media like Facebook to market their brand, give some announcements, update news and other important information about their institution. However, their stakeholders create unofficial Facebook pages associated to their institution. These pages are areas for students mostly to react to posts, comment, give their opinion on a given topic and share their daily life online in an informal and casual way. These social media footprints were used in the data mining process to identify their discourse. With this, Universities and Colleges could form decision-making mediations and improve the quality of education and service they provide. The specific objectives of this study are: to create a workflow on how to analyze social media data; to use Naïve Bayes Algorithm in classifying the discourse of Philippine HEI stakeholders; and to deduce the results of data mining and recommend intervention activities to improve quality education. Knowledge Discovery Databases (KDD) was used in the study. The result of the data mining process is displayed through a word cloud and a dynamic graph visualizing the classifications of posts and comments. Social engagement, academics, emotions, health, policies and finances were identified as the SM discourse of Philippine HEI Stakeholders.
\end{abstract}

Keywords: data mining, social media, higher education institutions, Philippines, naïve bayes

\section{Introduction}

Education today is digitally revolutionized with the rapid use of Information and Communications Technology (ICT). It has changed the landscape of education especially on the increasing utilization of the internet. The most popular internet technology is the use of Social Media (SM) with high user engagement rates due to increased worldwide usage of smartphones and mobile devices. In 2019, statistics shows that out of 4.2 billion internet users, there are 3.397 billion active social media users [1]. In the 2018 report of We Are Social and Hootsuite, Philippines is the country that spends most time on SM and among the SM platforms, Facebook remains on the lead with 2.32 billion users.

SM is becoming more and more widespread in Higher Education Institutions worldwide [2]. It does not only offer the academic community to communicate beyond local or social boundaries, it also offers possibilities to share user-generated content like pictures, videos, opinions, interests and other forms of expressions. Though SM is used in education, it is noted that its purpose is for users' social engagement online. In fact, $71 \%$ of teachers use it for personal use [3]. Furthermore, a consumer insight service mentioned that more than $98 \%$ of college-aged students use SM [4]. Students for example share their daily activities and educational experience informally and casually in different SM sites [5]. In 2013, confessions of students from the University of the Philippines were raised on 'The Diliman Files Facebook Page'. Since then, similar pages have emerged in other colleges and universities in the country. Many of the posts talked about were love confessions and issues about income bracket-based discrimination on campus. These Facebook page secret files let SM users exercise their freedom of speech making universities helpless to go after them because they continue to hide on fictitious names and accounts [6].

\footnotetext{
+ Corresponding author. Tel.: +639984437471; +639776181680

E-mail address: joeyaviles@ punp.edu.ph; esquivel.rosanna@auf.edu.ph
} 
Data mining (DM) is used in the education sector to effectively address the challenges for improving the quality of education to provide new knowledge related to the educational processes. DM in education is used to develop models for improving both learning experiences and institutional effectiveness [7]. Furthermore, DM techniques have shown to be capable of mining huge data produced on SM sites. This is made probable by way of mining information from big data set generated on SM and converting them into understandable form for further use [8].

Though there are many applications of DM in education, there is little empirical research conducted to analyse amorphous SM data in this sector. [9] recommended in their study that the area of SM calls for more profound research that takes into account accurate implementation of DM techniques in the academic sector. It is in this context that this study was ideated. This study dealt on mining SM data specifically on users' post and comments from Facebook pages among selected HEIs in the Philippines using Naïve Bayes classifier.

\section{Review of Related Literature}

Individuals, companies, organizations and even the government of different countries track the activities of their audience on SM to get information on how people react to their posts [8] They are conscious on the significance of the sentiments of their stakeholders as posted in SM to protect their image and for further development of their products and services. The core functionalities of DM include applying various methods and algorithms to discover useful patterns among the data. It is capable of handling three prevailing arguments with SM data which are volume, noise and dynamism [8]. Data can be mined with the following methods as mentioned by [10]: characterization, classification, regression, association, clustering, change detection, deviation detection, link analysis and sequential pattern mining.

Among the data mining methods, classification was used in this study, mining SM data from unofficial Facebook pages of HEIs which is explicitly discussed in the succeeding sections.

[11] used tweets ending in positive and negative emoticons, then build models using Naïve Bayes, MaxEnt and SVM. [12] also reviewed several techniques in mining SM data. The Study illustrated some applications of DM, specifically in telecommunication industry, to support customer satisfaction and maintain customer relationship. The techniques used were text mining, clustering and visualization. A similar study was also conducted by [13]. It focuses on Filipino internet customers' satisfaction associated to the service quality provided by the Internet Service Providers (ISPs). To identify the frequent words used to express the sentiments of customers and the polarity of opinions, naïve bayes method was used. The downside of the study were various factors that are causal to low performance. These are ambiguity of synonyms and antonyms of words in online dictionary, use of urban words, Short Message (SMS), tools on language translation, colloquial language, and long words.

Among the DM Techniques reviewed by [9], Support Vector Machine (SVM), Bayesian Network (BN), and Decision Tree (DT) were identified as the most applied techniques in the area of social media with a percentage of $51 \%$ of the selected articles reviewed. A study using Naïve Bayes Classifier from random sample of streaming Facebook statuses was used in the study conducted by [14] in using SA for language learning. The study of [15] pays attention on engineering students' tweets on Twitter to know the latter's problems and troubles in their educational practices. It is found out that engineering students encounter problems such as heavy learning load, lack of social meeting, and sleep deficiency. Based on this outcome, Naïve Bayes Multi-label Classifier algorithm is applied to categorize tweets presenting student's problems. The study of [5] explored on understanding engineering students' experiences by integrating both qualitative methods and large-scale data mining techniques. Through Qualitative content analysis and Naïve Bayes Multi-Label Classifier, the study found out that heavy study load is mostly the biggest problem of engineering students of Purdue University. This problem further leads to many consequences including lack of social engagement, sleep problems and other psychological and physical health problems.

With these literatures cited, it could be noted that the best classifier to be used with social media dataset is Naïve Bayes. However, the data of most researches in data mining social media are from Twitter. Thus, this study delved on gathering Facebook data specific to HEI pages then eventually do text classification using Naïve Bayes Classifier. 


\section{Methods}

\subsection{Research design and methodology}

Descriptive research design was used in this study. This kind of research design is a scientific method which involves describing the behaviour of a subject without influencing it in any way [16]. The researchers followed the Knowledge Discovery Databases (KDD) processes. KDD is an automatic, exploratory analysis and modelling of large data repositories. The process of which is organized to identify valid, novel, useful and understandable patterns from huge and complex data sets. It is a broad process of finding knowledge in data and emphasizes high-level application of particular data mining methods according to the specifications of measures and thresholds using a database along with any required pre-processing, subsampling, and transformations of that database [17].

\subsection{Software development}

In developing the system, the researchers made use of Extreme Programming or XP which is an approach in software development that is based on simplicity, communication, respect, feedback and courage [18]. It is software development framework utilizing the principles of agile development aiming to produce high quality software. The phases for XP are planning, designing, coding, testing and listening. The system was developed with HTML5, CSS3, AngularJS, NodeJS and MongoDB.

\subsection{Sources of data}

The main source of data are the text data from posts and comments on Facebook pages of public and private HEIs in Region 1, Philippines. The target Facebook pages are those page names with 'Secret Files'. This is where SM users usually post their concerns and experiences related to their HEI.

\subsection{Population and locale of the study}

Of the 17 regions in the Philippines, the collection of data focused in the Ilocos Region (Region 1) where there are 116 private and public colleges and universities. With 5\% of margin error and $95 \%$ confidence level, the sample size for the data collection is 84 HEIs. However, out of the selected HEIs, there were only $48.81 \%$ or 41 with 'Secret Files' page where the data were collected.

\subsection{Data gathering and processing procedures}

In getting the SM Data, the researchers made use of Facepager, a system made for fetching data from JSON-based APIs like Facebook. The text posts and comments collected are varied in form. They are written in English, Filipino, Ilocano or mixed. With this, translation was needed using google translate add-on. Words that were not recognized in the machine translation remained as is in the system. The researchers used inductive content analysis on the data set to discover what the SM users are saying in their posts and comments. In the initial categorization, the researchers developed categories including: love confessions, teacher-problems, school policies, school fees, lifestyle, curriculum and assessment, and family. These were developed to determine as many topics as possible. After reviewing and consulting other researchers and school administrators, the researchers concentrated the categories to: academics, social engagement, emotions, finances, policies and health. Considering the 9459 post and comments and the dominant categories, the researchers randomly selected 500 post and comments per category. Overall, there were 3000 labelled posts and comments used for training and testing.

\section{Discussion of Findings}

\subsection{Workflow used in analyzing SM data}

A web-based application was developed in this study to dynamically classify the posts and comments in Facebook pages of HEIs. Figure 1 illustrates how the data were collected, cleansed and transformed into a valuable information. 
Using access tokens that conform to the OAuth 2.0 protocol, the Facebook data are fetched through Facebook Graph API v. 3.2. For the machine learning algorithm to better understand the data, the researchers used translate my sheet add-on to translate the queried messages and posts to English. The translated data formed the corpus for classification. However, a limitation of this process is that, there are colloquial words that cannot be translated to English and therefore remained as it is in the system. After translation, the corpus undergoes data cleansing. The texts were transformed to lowercase. Numbers, punctuation marks, stop words and white spaces were also removed. From the cleaned data, sentiment analysis is performed to determine the positivity and negativity of the posts and comments as shown in Figure 2. The opinion lexicon used in the study for positive and negative sentiments are based on the study of [19]. The next step in the workflow is generating a word cloud which displays the most frequent words that are posted and commented in the respective HEI Facebook pages as shown in figure 3.

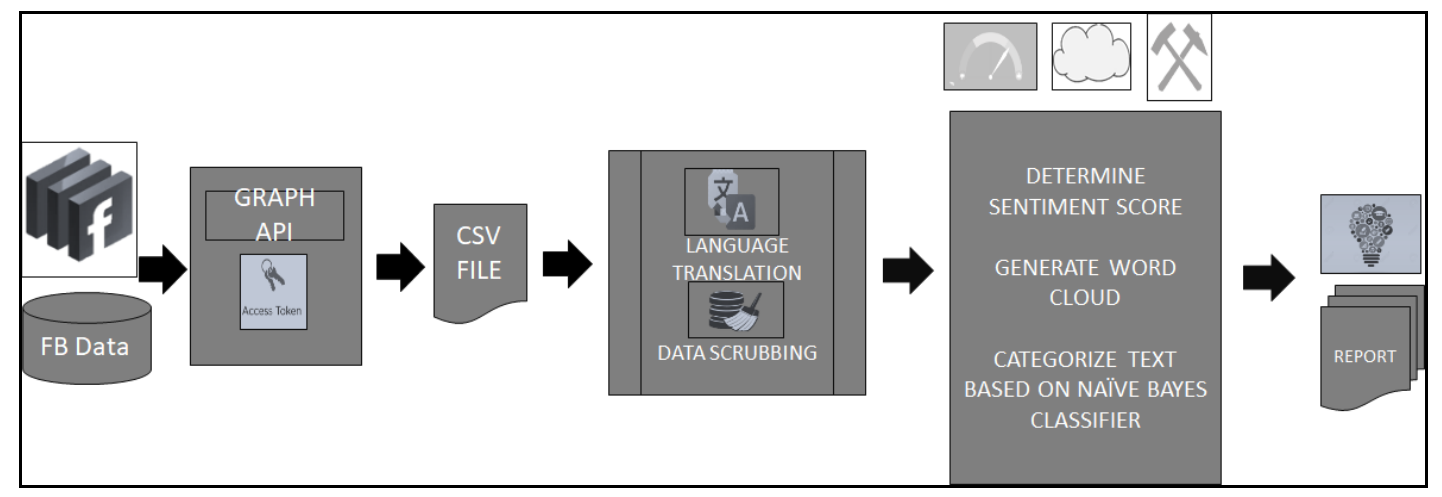

Fig. 1: Workflow used in Analyzing SM Data

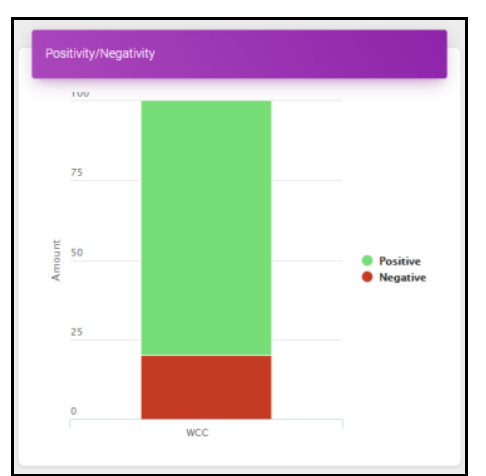

Fig. 2: Polarity of Posts and Comments

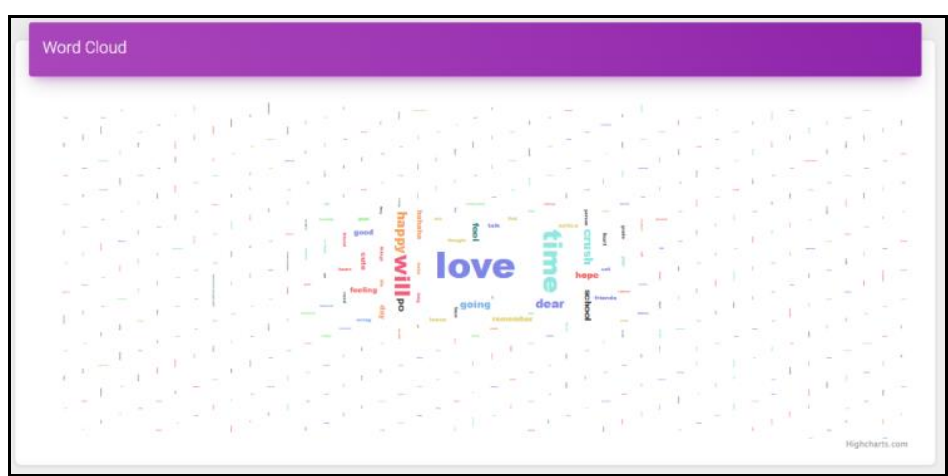

Fig. 3: Generated Word Cloud

The final step is classifying the words using the Naïve Bayes Algorithm. In predicting the class where the test data falls into, we get the priors multiplied by all of the features or conditional probabilities of a specific class. A sample visualization of the classification is shown in figure 4.

$$
\hat{c}=\max _{c \in C} \operatorname{Pr}(c) \prod_{i=1}^{n} \operatorname{Pr}\left(w_{i} \mid c\right)
$$

\section{Formula 1: Naïve Bayes Classification}

\subsection{Discourse of HEI Stakeholders}

The result shows that most of the discourse are positive with an average score of 0.02827 . Most posts and comments are related to social engagement with an average probability of .0430 followed by academics, emotions, health, policies and finances with average probability of $.0376, .00698, .00447, .00443$, and .00437 respectively. This is so because most of the SM users are students whose intention in using social networking sites like Facebook is for social relationships [20]. This finding supports the study of [21] that states that social engagement can provide support for releasing stress and is helpful in learning. Moreover, these students are mostly in their adolescent stage where group interactions [22] and social relationships are particularly important [23]. Reports revealed that using online technology like social media increases selfesteem, social support, social capital, safe identity experimentation and opportunity for self-disclosure [24]. 


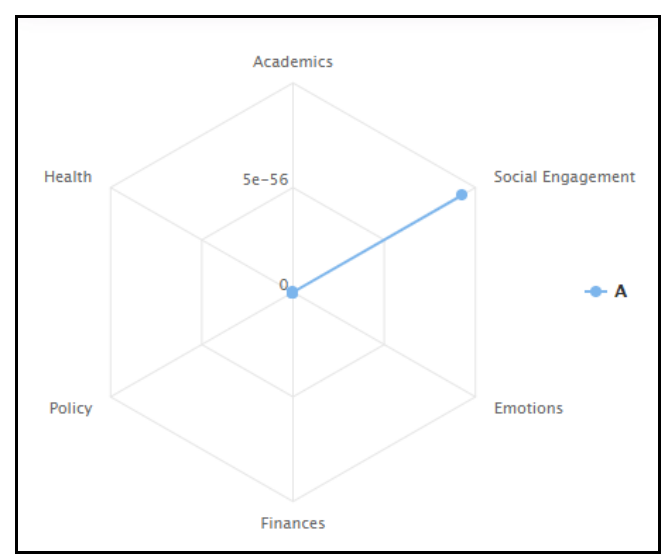

Fig. 4: Sample Classification Visualization from one HEI

These results also prove the developmental theory asserting that adolescents display cross-situational continuity in their social behaviours and recommend that the continuity of this conceptualization may be stretched into the online domain [25]. This however is in contrast to public anxiety as mentioned by [26] that social media distracts from education and reduces the social skills of young people-despite an exemplary body of prior research that reject such simple conclusions.

Social media is a platform for users to post their feelings and emotions. Student post positive feelings like showing their affection to someone. With this, feedback on their profiles enhance their self-esteem and well-being [27]. They feel overjoyed when they get some reactions like 'likes' and 'comments'. As mentioned by [26] SM emphasizes more temporary pleasures creating stress over public appearance. Moreover, SM provides students a direct medium to publicly evaluate and comment their campus environment, policies of their school, classes, professors, school administrators and fellow students [28]. Students post their academic concerns in social media because this type of platform poses liberal environment for them to discuss their views and opinions on issues that otherwise would not have been possible in a face-to-face classroom [28]. As mentioned in the study of [29], likelihoods of self-worth distinctively contribute to academic and financial problems experienced by freshmen college students beyond level of self-esteem and other personality variables which uniquely contribute to later social difficulties.

Moreover, Bigger financial problems may lead students to reduce coursework or drop out of school [30]. Noticeably, discourses of SM user are also on health. As cited by [31], students reported that stress and sleep difficulties negatively impacted their academic performance. Moreover, many college students engage themselves in unhealthy behaviours, making them at risk for developing serious problems in health in the future. As revealed by [32], college students show symptoms constant with depression on social media sites like Facebook. Given the frequency of depression symptoms, SM sites could be a platform to combat stigma surrounding metal health conditions or for identifying risks of students towards depression. Moreover, another discourse of students is on school policies which affect their experiences. Instructional decisions for example affect students' feelings about the curriculum [33].

\subsection{Proposed proactive and knowledge-driven decision intervention measures}

With the results of this study, the following intervention measures of HEIs are suggested:

- A framework on digital strategy for higher education can be researched on and further used where all the departments of an institution are related and integrated and move towards online presence. As said by [34] affirming that HEI social media presence is as important as generating high-quality leads and prospects. Education should be reformed and emphasize on digital literacy [35]. [36] also suggested to research into how social media influences the classroom and the non-pedagogical HE practices including administration, research, organizational learning, professional development and the values of academia as a profession. 
- Rules and Regulations of the University should be amended to integrate expected student behaviour online most especially in social media. There should be policies for the implementation of SM in ways that are likely to have a positive impact on student levels of engagement as suggested by [37].

- HEIs should strengthen their social media presence to highlight their branding and secure their information.

- HEIs should integrate socio-relational activities in the curriculum across programs. Activities and programs should focus on impacting social development which also focused on social emotional learning (SEL), thus creating a balanced curriculum that integrates academic and social or emotional learning [38].

\section{Conclusions and Recommendations}

The discourse of Philippine HEI stakeholders in SM is on social engagement followed by academics, emotions, health, policies and finances. Although we could identify as to where the posts and comments are classified, the performance of the Naïve Bayes algorithm is still low because of the machine translation. The translation tool was not able to accurately translate the posts and comments from filipino and ilokano to english. In addition, other words including colloquial terms and word abbreviations were not translated thus resulting for the algorithm not to establish the classification accurately.

With these results, the researchers recommend that future researches shall be taken on specifically on applying other data mining classification algorithm. To improve the performance of the developed system, other language translation tools and techniques may be used like online dictionary and part-of-speech (POS) tagging.

\section{Acknowledgements}

The Researchers would like to acknowledge the Commission on Higher Education, Panpacific University North Philippines - Tayug Campus and Angeles University Foundation.

\section{References}

[1] K. Smith. 123 Amazing Social Media Statistics and Facts. Retrieved from www.brandwatch.com: https://www.brandwatch.com/blog/amazing-social-media-statistics-and-facts/. 2019.

[2] L. Bexheti, B. Ismaili, B. Cico, B. An Analysis of Social Media Usage in Teaching and Learning. Recent Advances in Electrical and Computer Engineering. 2017.

[3] K. Seat. Surprising Statistics about Educators' Social Media Use. Direct Network. 2016.

[4] R. Griffin,. Social Media is Changing How College Students Deal with Mental Health, For Better or Worse. Retrieved from https://www.huffingtonpost.com/. 2019.

[5] X. Chen, M.Vorvoreanu, K. Madhavan,Mining Social Media Data for Understanding Students' Learning Experiences. IEEE Transactions on Learning Technologies, 2014.

[6] J. Estrada. Balancing Students' freedom of speech and expression in social media and the school's right to discipline. The Manila Tmes.2018.

[7] G. Kashyap and E. Chauhan. Review on Educational Data Mining Techniques. 2nd International Conference on Recent Innovations in Science, Engineering and Management. 2015.

[8] M. Olowe, M. Gaber, M., F. Stahl. A Survey of Data Mining Techniques for Social Media Analysis. School of Computing Science and Digital Media. Robert Gordon University. School of Systems Engineering. n.d.

[9] M. Injadat, F. Salo, A. Nasif. Data Mining Techniques in Social Media: A Survey. Neurocomputing http://dx.doi.org/10.1016/j.neucom.2016.06.045. 2016.

[10] J. Han and M. Kamber. Data Mining: Concept and Techniques. 2nd Edition. Morgan Kauffmann. 2006.

[11] A. Go, R. Bhayani, L. Huang. Twitter Sentiment Classification Using Distant Supervision. Technical Report. Stanford.2009. 
[12] V. Tundjungsari. Business Intelligence with Social Media and Data Mining to Support Customer Satisfaction in Telecommunication Industry. International Journal of Computer Science and Electronics Engineering. Vol. 1. Issue 1. ISSN 2320-4028. 2013.

[13] F. Patacsil, A. Malicdem, P. Fernandez. Estimating Filipino ISPs Customer Satisfaction Using Sentiment Analysis. Computer Science and Information Technology. 3(1): 8-13,2015. DOI: 10.13189/csit.2015.030102. 2015.

[14] C. Troussas, M. Virvou, K. Espinosa, J. Caro, J. Sentiment Analysis of Facebook Statuses using Naive Bayes Classifier for Language Learning. Department of Informatics. University of Piraeus, Greece. Department of Computer Science, University of the Philippines. Philippines.n.d.

[15] P. Pagare. Analyzing Social Media for Understanding Student's Problem. International Journal of Computer Applications. Innovations and Trends in Computer and Communication Engineering.2014.

[16] M. Shuttleworth. Descriptive Research Design. Retrieved from https://explorable.com/: https://explorable.com/descriptive-research-design. 2019.

[17] U. Fayadd, G. Piatesky-Shapiro, P. Smyth. From Data Mining to Knowledge Discovery Databases. AAAI Press. The MIT Press, Massachusetts Institute Of Technology. ISBN 0-26256097-6. 1996

[18] D. Wells. Extreme Programming: A gentile Introduction. 2013.

[19] M. Hu and B. Liu. Mining and Summarizing Customer Reviews. ACM SIGKDD International Conference on Knowledge Discovery and Data Mining. 2004.

[20] C. Cheung, P. Chiu, M. Lee. Online Social Networks: Why do students use facebook. Computers in Human Behavior. 2011

[21] S. Cohen, and T. Wills. Stress, Social Support, and the Buffering Hypothesis. 1985.

[22] R. Lerner and L. Steinberg. Handbook of Adolescent Psychology. New York: Wiley. 2004.

[23] S. Choudhury, S. Blakemore, T. Charman. Social Cognitive during the adolescence. Social Cognitive and Affective Neuroscience. 2006.

[24] P. Best, R. Manktelow, B. Taylor. Online communication, social media and adolescent well-being : A systematic narrative review. Children and Youth Services Review. 2014.

[25] A. Mikami, D. Szwedo, J. Allen, M. Evans, A. Hare. Adolescent peer realationships and behavior problems predict young adults' communication on social networking websites. Developmental Psychology. 2010.

[26] D. Miller, E. Costa, N. Haynes, T. McDonald, R. Nicolescu, J. Sinanan, X. Wang. How the World Changed Social Media. UCL Press. 2016.

[27] P. Valkenburg, J. Peter, A.Schouten. Friend Networking Sites and their Relationship to Adolescent's Well-being and Social Self-Esteem. CyberPsychology and Behavior. 2006.

[28] R. Boateng, A. Amankwaa. The Impact of Social Media on Student Academic Life in Higher Education. Global Journal of Human-Social Science: G Linguistics and Education. 2016.

[29] J. Crocker and R. Luhtanen. Level of Self-Esteem and Contingencies of Self-Worth: Unique Effects on Academic, Social, and Financial Problems in College Students. Personal and Social Pyschology Bulletin. 2003.

[30] S. Joo, D. Durband, J. Grable. The Academic Impact of Financial Stress in College Students. Journal of College Retention: Research, Theory \& Practice. 2009.

[31] D. Baldwin, K. Towler, M. Oliver II, S. Datta. An examination of college student wellness: A research and liberal arts perspective. Health Psychology Open.2017.

[32] M. Moreno, L. Jelenchick, K. Egan, E. Cox, H. Young, K. Gannon, T. Becker. Feeling Bad on Facebook: depression disclousures by college students on a social networking site. Depression and Anxiety. 2011

[33] C. Danielson. Enhancing Student Achievement. 2002.

[34] Y. Dwivedi, M. Mantymaki, M. Clement, E. Slade, N. Rana, S. Al-Sharhan, A. Simintiras. Social Media: The Good, the Bad, and the Ugly. 15th IFIP WG 6.11 Conference on e-Business, e-Services, and e-Society, I3E 2016 Swansea, UK. 2016.

[35] V. Giang. Millennials Will Lose 'Face-To-Face Social Skills' And 'Deep-Thinking Capabilities' By 2020. Retrieved from Business Insider: https://www.businessinsider.com/. 2019. 
[36] A. Manca, A. Whitwort. Social Media and Workplace Practices in Higher Education Institutions: A Review. The Journal of Social Media in Society. 2018.

[37] E. Ivala and D. Gachago. Social media for enhancing student engagement: The use of Facebook and blogs at a University of Technology. 2012.

[38] K. Merrell and B. Guelder. Social and emotional learning in the classroom: Promoting mental health and academic success. New York: Guilford Press. 2010. 